\title{
A compact purifying tank to treat sewage in rural area of China: lab-scale and field-scale study
}

\author{
Chang Wang ${ }^{1}$, Denghui Wang ${ }^{1}$, Jie $\mathrm{Hu}^{1}$, Ming Zeng ${ }^{1}$ \\ ${ }^{1}$ College of Marine and Environmental Science, Tianjin University of Science \&Technology, 300457 \\ Tianjin, China; \\ Email: ming.zeng@tust.edu.cn
}

Keywords: biofilm, bioreactor, engineering, wastewater.

\begin{abstract}
In China, the conditions of rural areas are quite different. The dispersed household and terrain difference allow the centralized system of sewage treatment being a challeng. Thus, it is urgent to set up the new mode of sewage treatment by buiding the highly efficient dispersed in-situ treatment engineering, which should be gauranted a long life time. Our group develop a novel purifying tank system based on the scientific research and enginnering experence, and propse the guidance of sewage treatment in rural area of China as well. Besdies the scientific work in the laboratory, several enginnering are carried out for various living modes in rural aerea. Specifically, the purifying tank combined with hydrolysis tank show a good performance in treating the sewage from single household, multi housholds, villa, apartment and small enterprise. The discharged water is prove to satisfy the discharging standard of Chinese goverment.
\end{abstract}

\section{Introduction}

Domestic wastewater is a major source of rural environmental pollution. In China, the rural population is about 9.1 hundred million, accounting for $70 \%$ of the total national population. Each year about 19 million tons of Biological Oxygen Demand (BOD) is discharged into the environment by the rural population according to the BOD loading rate of $40 \mathrm{~g} /$ person/day [1]. This great amount of BOD can contaminate the rural water resource if the treatment performance is not conducted. Different from the urban areas, the population living in small villages are usually scattered in the countryside, so it is unable to set up centralized public sewer collection systems in such areas [2]. Moreover, it is a great challenge to treat the household sewage owing to its characteristics of decentralized discharge, great variation of hydraulic loading rate and abundant solid matter from toilet and kitchen. Among various different technologies for municipal wastewater treatment in China, a compact multi-function purifying tank for the treatment of domestic sewage from single household has the advantages of low energy consumption, few produced sludge, low cost of installation and easy maintenance. As a decentralized technique, this compact purifying tank has been applied in certain small towns and scattered countryside in China [3]. It is practical to widely apply this compact purifying tank in small towns and scattered areas in China.

In this paper, the purifying tank system for the treatment of sewage in rural China is introduced. Our group spends several years to carry out the scientifc research and engineering application of this sytem. The experimental results of lab-scale purfiying tank and engineering projects of field-scale purifying system are concluded. Now, the guidance of setting up sewage treatment system is proposed: 1) the dispersed treatment way is favourable in treating the sewage in rural China because the problem of collecting water is the primery problem need to be resolved; 2) the sewage from the household is advised to be treated by the hydrolysis tank or the anearobic zone in purifying tank, in order to turn the large particlar to the soluable small particlar. This can prevent the clogging of pipes and decrease the pollutant loading rate in the following process. 


\section{Materials and methods}

The lab-scale purifying tank was made of organic glass, consisting of four zones in Fig. 1a. The volume of lab-scale tank was $1 / 132$ of the field-scale purifying tank that typically received the sewage loading rate of 1 ton per 5 persons per day. Thus the water influent flow was $7.5 \mathrm{~L} / \mathrm{d}$ for the lab-scale tank. The aeration rate was $3.28 \mathrm{~m}^{3} /\left(\mathrm{m}^{3} \cdot \mathrm{h}\right)$. The biofilm in reactors was fed with the real domestic sewage collected from Tianjin University of Science and Technology. The sewage was stored in a tank and the main characteristics of the influent sewage were COD $=441 \mathrm{mg} / \mathrm{L}, \mathrm{BOD}=$ $215 \mathrm{mg} / \mathrm{L}$, turbidity $=159 \mathrm{NTU}, \mathrm{pH}=7.28, \mathrm{NH}_{4}{ }^{+}-\mathrm{N}=77.5 \mathrm{mg} / \mathrm{L}$. The aerobic biofilm were formed by feeding the real wastewater in aeration condition, and one third of wastewater was renewed each day to ensure the growth of biofilm.

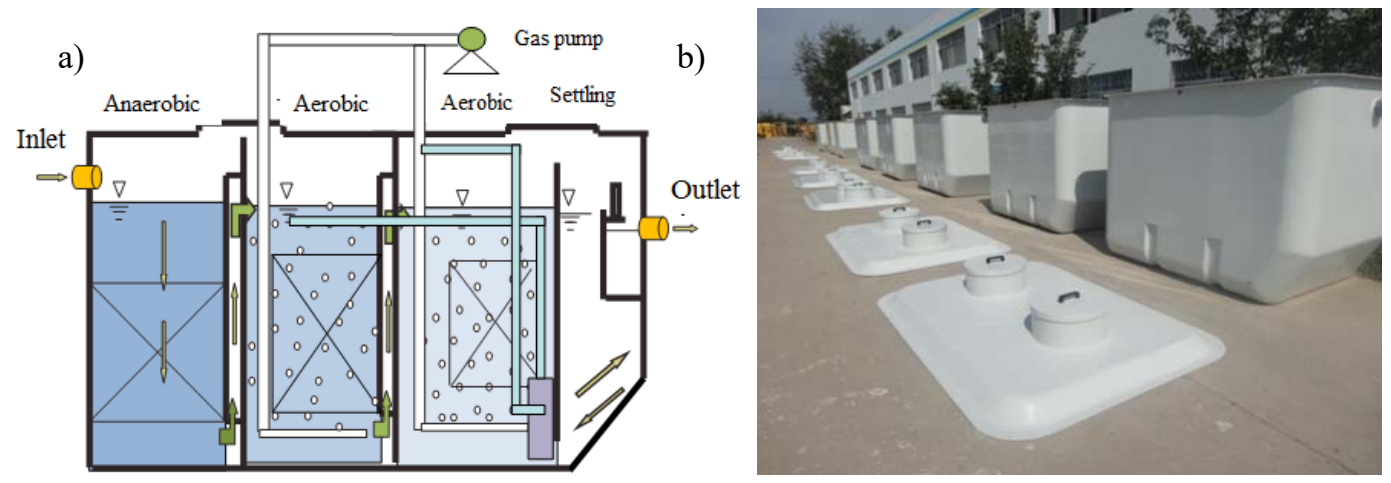

Figure1 Lab-scale (a) and field-scale (b) purifying tank

Figure $1 \mathrm{~b}$ shows the field-scale purifying tank that is applied in engineering. The volume is approximate $4 \mathrm{~m}^{3}$ with three independent zones for the biological treatment. The aeration mode in this zone can be changed according to the treating requirement. Moreover, the number of purifying tank and their combination is flexible for different treating objects.

\section{Results and discussion}

\subsection{Lab-scale purifying tank}

From 2007, the filter media, aeration rate, recirculation rate and hydraulic behavior of lab-scale purifying tank were discussed [4-7] to obtain the best operation condition, which offered the technical guidance for the engineering application. Firstly, the PE corrugated plate carrier was found to be the optimum support media for the biofilm with fast inoculation speed. After one week, there was a biofilm membrane evenly on the surface of carrier. Additionally, it contributed to the high removal efficiency of pollutant, simple installation and enough resistance to the hydraulic loading variation [4]. Secondly, the aeration rate had a close relationship with performance of purifying tank. The removal efficiency of pollutant increased with the increase of aeration rate, and the effluent concentrations of COD, BOD, $\mathrm{NH}_{4}{ }^{+}-\mathrm{N}$ and DO arrived at 46, 9.6, 23.8, $2.11 \mathrm{mg} / \mathrm{L}$ when the aeration rate reached $3.28 \mathrm{~m}^{3} /\left(\mathrm{m}^{-3} \cdot \mathrm{h}^{-1}\right)$ [5]. Thirdly, the hydrodynamic behavior of lab-scale purifying tank was investigated by using $\mathrm{KCl}$ and ink tracing test. The plug flow pattern was found in anaerobic zone, while the completely stirred tank pattern was found in the aerobic zone due to the aeration. This hydrodynamic behavior inhibited the pollutant of influent with high concentration entering into the following zone, while the biofilm in the aerobic zone can easily treat the digested sewage [6]. Finally, based on the purifying tank for the single household, the purifying tank combined with hydrolysis tank was developed for the multi households. Besides, the two-step anaerobic and one-step aerobic processes in the original purifying tank were changed to the one-step anaerobic and two-step aerobic processes to treat influent discharged from multi households. Table 1 show that the novel purifying tank could improve the treating capacity of 4 times with the same treating efficiency. The effluent BOD concentration arrived at $13 \mathrm{mg} / \mathrm{L}$, and the novel purifying tank system can extremely cost the energy by decreasing the power consumption from $1.5 \mathrm{kWh} /$ ton to $0.5 \mathrm{kWh} / \mathrm{ton}$ [7]. 
Table 1 Comparing performances of traditional and novel purifying-tank system

\begin{tabular}{lllllll}
\hline Purifying tank & Household & BOD $_{\text {in }}$ & HLR & BOD $_{\text {loading }}$ & $\mathrm{BOD}_{\text {out }}$ & $\begin{array}{l}\text { Consumed } \\
\text { power }\end{array}$ \\
& & $\mathrm{mg} / \mathrm{L}$ & $\mathrm{L} / \mathrm{d}$ & $\mathrm{g} / \mathrm{d}$ & $\mathrm{mg} / \mathrm{L}$ & $\mathrm{kWh} / \mathrm{ton}$ \\
\hline Traditional & 1 & 228 & 7.5 & 1.71 & 12 & 1.5 \\
Novel & 5 & 141 & 30 & 4.23 & 13 & 0.5 \\
\hline
\end{tabular}

\subsection{Field-scale purifying tank}

Since 2008, three traditional purifying tanks were installed and operated in three household in Diliufu village of Xiqin district in Tianjin city of China. The engineering was strictly conducted without additional human management. Table 2 indicated that the effluent BOD concentration decreased to $16.5 \mathrm{mg} / \mathrm{L}$ only after 18 days of inoculation. This vale satisfies the national discharge standard of treated municipal wastewater. Moreover, the effluent BOD concentration arrived at the first-class discharge standard, lower than $20 \mathrm{mg} / \mathrm{L}$ after one year of operation. The COD and SS concentration also arrive at the second-class discharge standard. Thus, the effluent was used to irrigate vegetation or directly discharged in to the river. This cost of sewage treatment was 0.75 yuan/ton. Figure 2 show the treating results in the different zones of purifying tank. It is obvious that there were residues of fermentation and biogas in the anaerobic zone, while the effluent in the aerobic zone was remarkably clear.

Table 2 BOD concentration in different zones before and after inoculation (unit: $\mathrm{mg} / \mathrm{L}$ )

\begin{tabular}{lllll}
\hline & $\begin{array}{l}\text { Before } \\
\text { inoculation } \\
07 / 11 / 2008\end{array}$ & $\begin{array}{l}8 \text { days } \\
\text { after inoculation } \\
15 / 11 / 2008\end{array}$ & $\begin{array}{l}18 \text { days } \\
\text { after } \\
\text { inoculation } \\
25 / 11 / 2008\end{array}$ & $25 / 03 / 2009$ \\
\hline Influent at inlet & 275.4 & 263 & 268 & 259.0 \\
Effluent after 1 $^{\text {st }}$ anaerobic zone & 248.2 & 210.1 & 209.3 & 201.4 \\
Effluent after 2 $^{\text {nd }}$ anaerobic zone & 180.3 & 115.6 & 97.7 & 95.1 \\
Effluent after last aerobic zone & 66.2 & 32.2 & 23.6 & 26.6 \\
Effluent at outlet & 64.3 & 19.3 & 16.5 & 18.5 \\
\hline
\end{tabular}

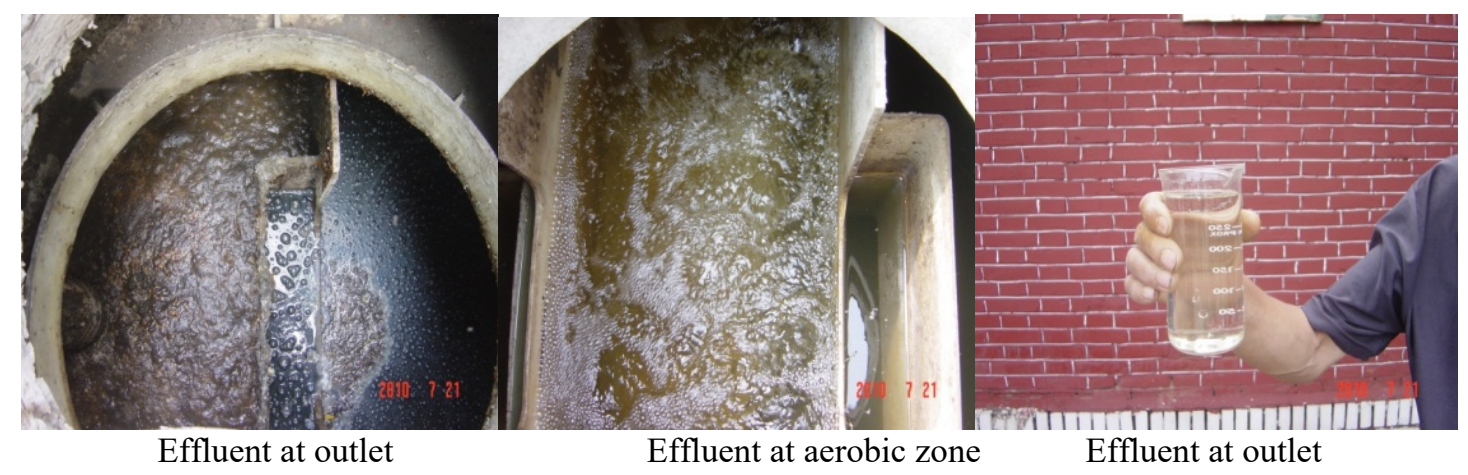

Figure 2 Treating results in the different zones of purifying tank

The engineering of novel purifying tank system for multi households were carried out at Huifengxi village in Jinhai district of Tianjin, China. There are 138 households with 483 habitants in this area. According to the terrain difference, dispersed treatment method was adopted including the purifying tank for five single household and novel purifying tank with hydrolysis tank for multi households. The treating capacity arrived at $20 \mathrm{t} /$ day. Figure 3 show the schematic diagram of purifying tank with hydrolysis tank for the five households. For the multi households, sewage from each household was collected in the hydraolyis tank immediately to prevent the clogging of pipe to the purifying tank. The effluent BOD concentration stayed lower than $10 \mathrm{mg} / \mathrm{L}$ even when the influent BOD reached 200 
$\mathrm{mg} / \mathrm{L}$ by this in-situ treating system.

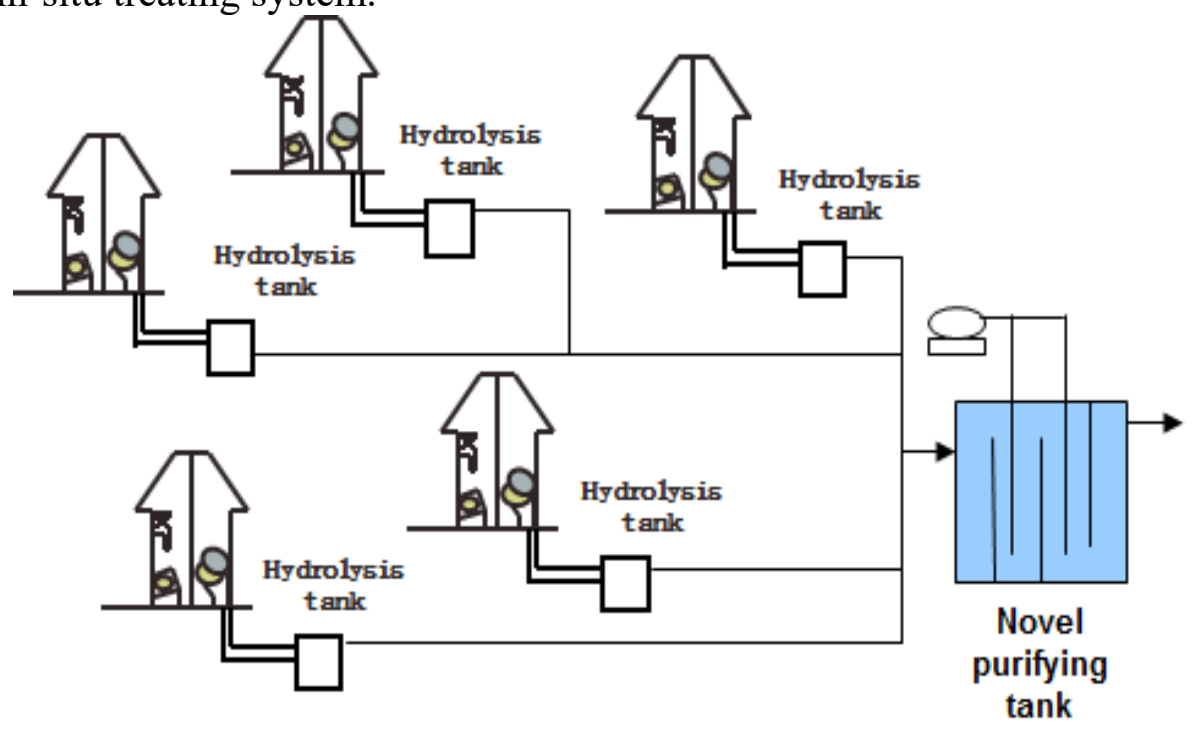

Figure 3 Schematic diagram of purifying tank with hydrolysis tank for the five households

\section{Summary}

In recent decant, our group carried out comprehensive work in the area of sewage treatment in rural China, containing the lab-scale scientific research, as well as the engineering applications in rural villages. The guidance of sewage treatment in rural area is proposed based on these experiences. Specifically, the dispersed treatment mode is the optimum approach, and the sewage from each household should enter into the hydrolysis tank or the anaerobic zone in the purifying tank. Afterwards, the purifying tank is able to remove pollutants, allowing the effluent meet the national standard of municipal wastewater discharge.

\section{Acknowledgements}

This work was supported by Project (2014CXLG12) and Project (10227) from Tianjin University of Science \&Technology; Project (201404140) supported by Agricultural Commission of Tianjin, China; Project (14ZCDGNC00097) supported by the science and Technology Commission of Tianjin, China.

\section{References}

[1] Liu X and Chen H B. The ecological treatment technique of sewage from villages and towns. China Water and Wastewater. Vol. 19(2003), p.32-35. (in Chinese)

[2] Xi B, Li X., Gao J, Zhao Y, et al. Review of challenges and strategies for balanced urban-rural environmental protection in China. Frontiers of Environmental Science \& Engineering, Vol. 9(2003), No. 3, p.32-35.

[3] Wu G Q, Sun X Y, Zhang Q S. Application of Purification Tank in Distributed Rural Sewage Treatment in China. Environmental Science and Technology, Vol. 6(2010), p.36-40. (in Chinese)

[4] Wang Z C, Wang C, Yuji S. Effect of different kinds of bio-filter on treatment of household sewage in purifying tank. Technology of Water Treatment, Vol. 37(2011), No. 2, p.81-84. (in Chinese)

[5] Wang $\mathrm{C}$, Liu J H, Li G J, et al. Influence of different aeration rates on domestic sewage treatment in purifying tank. Technology of Water Treatment, Vol. 35(2009), No. 5, p.35-39 (in Chinese)

[6] Wang R, Wang C, Yuji S. Study on compact house sewage purifying-tank with natural flowing process. Environmental engineering, Vol. 25(2007), No. 5, p.21-24. (in Chinese)

[7] Wang C, Li L, Tan Y Q. Study on treatment of household sewage in purifying tank connecting multiple septic tanks. Environmental engineering, Vol. 30(2012), No. 2, p.26-29. (in Chinese) 